\title{
A EXPERIÊNCIA DE SER MÃE DE UM FILHO COM AUTISMO NO CONTEXTO DA MONOPARENTALIDADE
}

\author{
THE EXPERIENCE OF BEING A MOTHER OF A CHILD WITH AUTISM IN THE SINGLE- \\ PARENTHOOD CONTEXT
}

\section{LA EXPERIENCIA DE SER MADRE DE UN HIJO CON AUTISMO EN EL CONTEXTO DE LA FAMILIA MONOPARENTAL}

\author{
Marilise Ferreira* \\ Luciane Najar Smeha ${ }^{* *}$
}

\begin{abstract}
RESUMO
Este estudo objetivou conhecer a experiência de ser mãe de um filho com autismo no contexto da monoparetalidade. Foi realizada uma pesquisa qualitativa, na qual participaram quatro mães de filhos com transtorno do espectro autista. Utilizou-se de entrevista semiestruturada. Posteriormente, os dados foram submetidos à análise textual qualitativa. Os resultados revelaram que os sentimentos e desafios são semelhantes aos de mães de filhos com autismo que não vivem no contexto monoparental. Acredita-se que a diferença possa estar na intensidade, isto é, na monoparentalidade, as dificuldades podem ser agravadas pela ausência de um companheiro. Sobre a possibilidade de um novo relacionamento afetivo, quando há, mesmo que remota, não está centrada na necessidade de auxílio nos cuidados com o filho, mas no apoio emocional. Entre os fatores que contribuem para a manutenção da monoparentalidade, destacam-se a priorização do papel materno, a adolescência do filho, além de uma rede de apoio restrita.
\end{abstract}

Palavras-chaves: Maternidade. Transtorno do espectro autista. Família monoparental.

\begin{abstract}
This study aimed to learn about the experience of mothering a child with Autism in a single-parent context. Four mothers of children diagnosed with Autism Spectrum Disorder were the subjects of a qualitative research. A semi-structured interview was used. Afterwards, the data were submitted to qualitative textual analysis. The results revealed that the feelings and challenges they experience are similar to those from mothers who are not in the single-parent context. It is believed that the difference might be
\end{abstract}

\footnotetext{
Texto recebido em $1^{\circ}$ de abril de 2015 e aprovado para publicação em $1^{\circ}$ de fevereiro de 2016.

"Mestranda no Programa de Pós-Graduação em Psicologia da Universidade Federal de Santa Maria (UFSM), graduada em Psicologia pelo Centro Universitário Franciscano (Unifra).E-mail: mary_f100@hotmail.com.

**Doutora em Psicologia pela PUC do Rio Grande do Sul, docente no curso de Psicologia do Centro Universitário Franciscano. E-mail: lucianenajar@yahoo.com.br.
} 
concerning the intensity, that is, in the single-parent context, as the difficulties might be enhanced due to the absence of a partner. About the possibility of a new emotional relationship, when there is one, though remote, it is not centered on the need for help to provide childcare but to gain emotional support. Among the factors that contribute to the maintenance of singleparenting, we can highlight the prioritization of the mother role, the child's adolescence in addition to a restrict supportive back-up.

Keywords: Maternity. Autism spectrum disorder. Single-parent family.

\section{RESUMEN}

El objetivo de este estudio fue conocer la experiencia de ser madre de un niño con autismo en el contexto de familias monoparentales. Fue realizada una investigación cualitativa, en la cual participaron cuatro madres de hijos con trastorno del Espectro Autista. Fueron utilizadas entrevistas semiestructuradas y posteriormente, los datos fueron sometidos al análisis textual cualitativo. Los resultados revelaron que los sentimientos y desafíos son semejantes a los de madres de niños con autismo que no viven en contexto monoparental. Se cree que la diferencia pueda estar en la intensidad, esto es, en la monoparentalidad, las dificultades pueden ser agravadas por la ausencia de un compañero. Sobre la posibilidad de una nueva relación afectiva, cuando existe, aunque sea remota, no está centrada en la necesidad de auxilio en los cuidados con el hijo, pero sí en el apoyo emocional. Entre los factores que pueden contribuir al mantenimiento de la monoparentalidad, destacamos la priorización de la función materna y la adolescencia del niño, además de una red de apoyo restringida.

Palabras clave: Maternidad. Trastorno del espectro autista. Familia monoparental.

\section{INTRODUÇÃO}

Vários estudos contemplam o tema da configuração monoparental, com base em diversos enfoques (Hernández, 2013; Marin \& Piccinini, 2009; Lucas, 2012; Yunes, Garcia \& Albuquerque, 2007; Fialho, 2004; Correia, 2002). Pela pesquisa na literatura, percebe-se que a família monoparental não representa uma nova configuração, pois ela sempre esteve presente na história como uma das formas de ser família (Hernández, 2013).

Em 1960, na Inglaterra, iniciou-se o reconhecimento da família monoparental, diante do número significativo de situaçôes de monoparentalidade. Assim, encara tal configuração familiar com mais naturalidade, percebendo que essa advinha, com maior frequência, de classes mais baixas, recebendo o nome de "família de parentes" (Palma, 2001). A expressão difundiu-se na Europa continental pela França que, no ano de 1981, cunhou o termo em uma pesquisa do Instituto 
Nacional de Estatística e de Estudos Econômicos (INSEE). Este se utilizou do termo para diferenciar as uniōes formadas por um casal daqueles lares constituídos por um progenitor solteiro, viúvo, divorciado ou separado (Leite, 1997).

$\mathrm{Na}$ França, foi percebido que essas famílias decorriam de uniões ou da formação por um só genitor por opção deste, passando essas a serem denominadas de monoparentais. A partir do reconhecimento de tal configuração na França, assim como pela Inglaterra, essa noção de família espalhou-se por toda a Europa e passou a representar a família formada por um dos pais e seus filhos (Palma, 2001). Assim, a família monoparental foi sendo reconhecida no Ocidente (Leite, 1997).

Conforme Lôbo (2009), esse tipo de família recebeu tutela explícita da Constituição, sendo caracterizada como uma família na qual há a presença de um dos pais e seus filhos menores, por diversas situações. Segundo Fialho (2004), no caso da família monoparental feminina, esse termo é utilizado para denominar laços familiares em que a mulher sozinha é responsável por seus filhos, em termos de educação e sustento, podendo esta ser solteira, separada ou viúva. De acordo com o Censo Demográfico de 2010 de Famílias e Domicílios (Instituto Brasileiro de Geografia e Estatística [IBGE], 2010), no que diz respeito à ocorrência de famílias monoparentais femininas, com ou sem parentes coabitando, houve aumento de 1 ponto percentual, de $15,3 \%$ para $16,2 \%$.

Algumas famílias monoparentais podem perpassar situações de dificuldade, enfrentando problemas inerentes à sua tipologia familiar. Entretanto, percebeuse que são capazes de se adaptarem adequadamente e viverem seu dia a dia (Lucas, 2012). Um diagnóstico de autismo pode ser um desses momentos difíceis, pois, conforme Grael (2007), diante de um filho com características muito atípicas, a dinâmica da família, a saúde dos pais e os papéis parentais ficam afetados, podendo trazer à tona o limite para o exercício da maternidade e paternidade idealizado. No atual Manual Diagnóstico e Estatístico de Transtornos Mentais - DSM-5 (American Psychiatric Association [APA], 2014), está presente o transtorno do espectro autista (TEA), no qual, entre outros critérios diagnósticos, está a existência de déficits persistentes na comunicação social e interação social em variados contextos e padrões restritos e repetitivos de comportamento, interesses ou atividades.

A literatura aponta alguns estudos que vêm investigando, direta ou indiretamente, o autismo e seus possíveis efeitos no sistema familiar (Graça, 2011; Semensato \& Bosa, 2013; Hernández, Gutiérrez, Zamalloa \& Mathews, 2012; Sprovieri \& Assumpção Júnior, 2001; Marques \& Dixe, 2011; Verdi, 2003; Schmidt \& Bosa, 2003), especialmente na experiência de maternidade (Smeha \& Cezar, 2011; Schmidt, 2004; Silva \& Ribeiro, 2012; Schmidt \& Bosa, 2007; Silva, 2010), diante dos cuidados delegados à figura da mãe, porém não as discute com frequência na configuração monoparental. 
A partir do exposto, no estudo, o objetivo foi conhecer a experiência de ser mãe de um filho com autismo no contexto da monoparentalidade, a fim de articular essas duas temáticas, levando em consideração o fato de as incidências desse diagnóstico e dessa configuração familiar estarem crescendo atualmente. No artigo, também se identificaram os sentimentos e desafios enfrentados pelas mães que viviam essa experiência, verificaram-se fatores que contribuem à construção e manutenção do modelo familiar monoparental, além de se conhecer a percepção dessas quanto à rede de apoio.

\section{MÉTODO}

O estudo foi baseado em uma pesquisa qualitativa, exploratória e descritiva com mães que estão dentro de uma configuração de monoparentalidade e que têm filho com diagnóstico de transtorno do espectro autista (TEA). A pesquisa contou com quatro participantes, as quais foram selecionadas, primeiramente, pelo critério de conveniência. A primeira mãe foi indicada pela rede de conhecidos da pesquisadora e, posteriormente, a amostragem foi constituída por meio de bola de neve, em que as mães entrevistadas foram indicando outras mães para o estudo. Elas estão identificadas como A, B, C e D, e os filhos, como “[x]", a fim de se preservar a identidade das mães e de seus filhos. Destaca-se a opção por participantes com características heterogêneas em relação, principalmente, ao tempo de monoparentalidade, o que propiciou, no estudo, conhecerem-se diferentes realidades.

Tabela 1. Dados informativos das participantes

\begin{tabular}{c|c|c|c|c} 
& A & B & C & D \\
\hline Idade & 56 anos & 31 anos & 47 anos & 50 anos \\
\hline Profissão & Secretária & Vendedora & $\begin{array}{c}\text { No momento, } \\
\text { não trabalha }\end{array}$ & $\begin{array}{c}\text { Contabilista, } \\
\text { mas, no } \\
\text { momento, } \\
\text { não exerce a } \\
\text { profissão }\end{array}$ \\
\hline $\begin{array}{c}\text { Estado civil/fator } \\
\text { determinante para a } \\
\text { monoparentalidade }\end{array}$ & Viúva & $\begin{array}{c}\text { Separada/ } \\
\text { divorciada }\end{array}$ & $\begin{array}{c}\text { Separada/ } \\
\text { divorciada }\end{array}$ & Viúva \\
\hline $\begin{array}{c}\text { Tempo de } \\
\text { monoparentalidade }\end{array}$ & 1 ano & 3 anos & 16 anos & 1 ano e meio \\
\hline $\begin{array}{c}\text { No de filhos } \\
\text { diagnóstico } \\
\text { de TEA })\end{array}$ & 1 & $\mathrm{R} \$ 1.500,00$ & $\mathrm{R} \$ 1.024,00$ & 1 \\
\hline $\begin{array}{c}\text { Idade dos filhos com } \\
\text { TEA }\end{array}$ & $\begin{array}{c}17 \text { anos } \\
\text { Fonte: }\end{array}$ & 4 anos & 17 anos & 17 anos \\
\hline
\end{tabular}

Fonte: dados da pesquisa. 
Para a coleta de dados, foi realizada uma entrevista semiestruturada com cada uma das mães participantes, perguntando-lhes sobre temas como o tempo de monoparentalidade, sobre como é a experiência de ser mãe de um filho com autismo em uma configuração monoparental e a diferença percebida dessa vivência para outra configuração experienciada. As participantes também foram questionadas quanto à sua percepção de rede de apoio, fatores que contribuíram para a construção e manutenção da monoparentalidade, sentimentos, desafios, entre outros.

Objetivou-se, assim, proporcionar às mães abertura para fornecerem informaçōes relevantes que transpõem as perguntas realizadas. Para a análise dos dados obtidos, utilizou-se a técnica de análise textual qualitativa que, segundo Moraes (2003), é constituída por três elementos: unitarização, categorização e comunicação, apresentando-se como um instrumento que possibilita a emergência de novas interpretações baseando-se na auto-organização.

Desse modo, baseando-se nessa técnica e autor, em um primeiro momento, foi realizada a fragmentação do texto obtido por meio da transcrição das entrevistas, a fim de focar em seus pormenores. Essa etapa permite a percepção dos vários sentidos do material. O próximo passo foi a categorização, na qual houve comparação das unidades de significado, agrupando-as com precisão, de acordo com suas semelhanças. A etapa seguinte foi direcionada a uma nova ordem e à emergência do novo, tratando-se de um processo auto-organizado, no qual houve a identificação de novos elementos que emergiram. Com a comunicação dos novos entendimentos alcançados por meio das etapas anteriores, constituiuse a terceira etapa. No entanto, foi necessário fazer com que o novo conteúdo, que antes não era compreensível, tornasse inteligível. Para atingir tal objetivo, elegeu-se um argumento central para que as categorias estabelecidas pudessem se integrar no todo. Assim, a análise textual qualitativa pôde ser definida como um método auto-organizado, em que novos significados foram construídos em relação aos objetos estudados. O processo resultou em três grandes categorias: do diagnóstico à rotina de cuidados; desafios e preocupações na experiência de maternidade; sentimentos vivenciados na experiência de maternidade na monoparentalidade; e rede de apoio e suas percepçôes.

Este estudo foi avaliado e aprovado pelo Comitê de Ética em Pesquisa do Centro Universitário Franciscano, CAAE: 32485614.0.0000.5306, e número do parecer: 709.636 . 


\section{APRESENTAÇÃO E DISCUSSÃO DOS RESULTADOS}

\subsection{Do diagnóstico à rotina de cuidados}

A maternidade, de forma geral, é uma fase de transição bastante complexa. Ela é delineada por momentos novos e, algumas vezes, estressantes (Rapoport \& Piccinini, 2006). Segundo o estudo de Smeha e Cezar (2011), a fase da confirmação diagnóstica de autismo do filho é muito importante à família, especialmente para a mãe, que passa a se organizar de uma forma mais eficaz para atender às necessidades de cuidado do filho.

Segundo Brazelton e Cramer (1992), os pais idealizam que esse filho terá sucesso em tudo aquilo que eles fracassaram. Quando um bebê nasce com alguma deficiência, para os pais, sobrepõe-se uma carga de luto e adaptação. Eles precisam transpor esse momento a fim de reorganizarem suas vidas (Sprovieri, 2007; Buscaglia, 1997). Conforme estudo de Rodrigues, Fonseca e Silva (2008), a expressão dessa "perda" do filho com o qual as mães da pesquisa sonharam se dava a partir de sentimentos de tristeza e frustração. As mães B e D do estudo relataram esse impacto do diagnóstico, todavia, a partir dele, ambas o encaram como um "correr atrás" e ir à busca de progresso no desenvolvimento do filho. "Falam nos livros que as mães, quando recebem o diagnóstico, entram em luto por terem perdido o filho perfeito, né? Até pode ser, só que daí a gente vê. Vi isso como "um vou correr atrás, vou dar o melhor pra ele" (B).

"Dificilmente os pais aceitam no primeiro momento [...] Tem que aceitar, tem que fazer correr atrás pra ver se tu tem o melhoramento... procurar ajuda dos terapeutas" (D).

É frequente que mães, assim como pais de filhos com autismo, perpassem por momentos de sofrimento psicológico, por uma fase de não aceitação da deficiência desse filho (Rodrigues, Fonseca \& Silva, 2008). No entanto, com o passar do tempo, sabe-se que a tendência é que a família se reorganize. A reorganização da família se dá após a superação desse momento inicial, que não tem um tempo previamente estabelecido para acontecer, pois depende de cada caso e da maneira como cada família reage às situaçôes novas (Sprovieri, 2007). $\mathrm{Na}$ pesquisa de Minatel e Matsukura (2014), percebeu-se que as dificuldades oriundas do transtorno e os meios de enfrentamento que podem ser alcançados, influenciam nas atividades do dia a dia e na forma de a família se organizar.

$\mathrm{Na}$ pesquisa de Schmidt e Bosa (2007), a mãe aparece como a principal responsável no que tange aos cuidadores de pessoas com TEA, como alimentação, medicação, vestuário, entre outros. No entanto, no caso deste estudo, essa responsabilização é inevitável diante do desempenho do papel parental que está, 
em decorrência da monoparentalidade, apenas sob a figura materna. Dentro dessa responsabilização, elas assumem a busca, por exemplo, por terapias que possam promover um melhor desenvolvimento para o filho, principalmente as mães B e D. "Tentar dar pra ele um suporte legal... De ele conseguir fazer coisas que outras crianças fazem... Tudo o que eu puder dar pra ele, vou dar pra ele" (B). "Tu tem que tá sempre atrás, sempre procurando, sempre inovando" (D).

Contudo essa busca demanda investimentos diversos das mães, que podem ser dificultados pela configuração monoparental. Para atender bem aos filhos, sentem-se sobrecarregadas, pois há necessidade de prover os recursos financeiros para seu sustento e, ao mesmo tempo, dispor de tempo para dar atenção e manter a qualidade de cuidado singular que uma pessoa com TEA requer, como exemplificam as mães $\mathrm{B}$ e C:

E eu ainda ganho por comissão. Se eu faltar não vou ganhar, se eu não ganhar eu não vou ter como... Porque tudo é pago [...] Não tenho a pensão, não tenho ajuda financeira de ninguém, então é eu. [Além disso,] Eu não tinha tempo. [...] Pra mim, o dia poderia ter umas 30 horas que tava começando a ficar bom (B).

"A gente combinou que ele ia pagar, mas daí ele não pagava. [Além disso,] Aí eu disse que não tinha tempo. Eu disse: não tenho tempo de ler o jornal” (C).

Portanto se percebem variadas responsabilidades a serem desempenhadas por essas mães sem terem essas a possibilidade de dividir o cuidado com o pai de seu filho ou um companheiro. Dessa forma, começam a emergir, ao longo dessa rotina, algumas dificuldades.

\subsection{Desafios e preocupações na experiência de maternidade}

Com relação aos desafios na tarefa de cuidar do filho com autismo, algumas mães apontam: "É uma coisa bem diária, sabe?" (B); "É o dia a dia" (D); ou "É que nem matar um leão por dia!" (B); ou ainda: "É uma caixinha de surpresa" (D). Percebe-se que há uma imprevisibilidade por trás desses desafios, ou seja, uma dificuldade quanto a não saber o que esperar em relação ao comportamento, desenvolvimento desse filho e de suas necessidades, que são relativas. O mesmo aparece nos resultados de Schmidt (2004), os comportamentos instáveis e imprevisíveis são percebidos como aspectos que podem promover estresse e dificultar a adaptação familiar ao quadro clínico. Isso também foi percebido nas mães deste estudo: "Todo o dia tu vai abrir aquela caixinha e vai ter uma surpresa" (D) e, diante disso, "A gente não tem a fórmula... hoje tá bem, amanhã, de repente, tá com uma crisezinha, no outro dia, pode surtar. Então tu sempre tem que tá preparada... e tu tem desafio todos os dias. [...] Não é fácil. Só quem 
tá dentro é que sabe. [...] O autismo é isso" (D). A experiência relatada elucida uma das especificidades de ter um filho com TEA, pois em uma criança com desenvolvimento típico, as características de cada etapa do desenvolvimento podem ser previstas com clareza.

Smeha e Cezar (2011) também apontam que essa experiência pode se tornar desafiante, visto que as mães precisam enfrentar o desconhecido. Entretanto essa imprevisibilidade é compreendida positivamente pela mãe B, ou seja, em termos de aquisição do desenvolvimento: "O meu desafio é cada dia uma palavra diferente dele, um gesto diferente, é uma cara diferente que ele faça, é uma pirraça diferente" (B). Isso pode estar relacionado à idade do filho da mãe B, já que, com 4 anos, a expectativa de progressos no desenvolvimento ainda é muito grande. $\mathrm{O}$ mesmo não se percebe nas outras três mães, uma vez que seus filhos já estão na adolescência.

Há também a questão do preconceito que parece preocupar ou incomodar algumas mães deste estudo. Elas passam por situações, nas quais se sentem expostas ao olhar do outro, pois, muitas vezes, o comportamento imprevisível dos filhos desperta constrangimento e preocupaçôes com o que os outros vão pensar sobre como elas exercem a maternidade. Conforme pesquisa de Schmidt, Dell'Aglio e Bosa (2007), aspectos comportamentais do transtorno, como agitação psicomotora, gritos ou agressividade, tornam-se difíceis de ser controlados, e quando estes emergem em ambiente público, por exemplo, acaba por se tornar, por vezes, inevitável o constrangimento pelo uso de uma intervenção mais diretiva como contenção física e, ou, retirada. Neste estudo, as mães A e B relataram: "Não precisávamos ter passado por tudo aquilo... se expor... porque $\mathrm{o}[\mathrm{x}]$ me bateu um dia dentro do avião... e uma pessoa disse assim: 'no mínimo ele apanha em casa'” (A).

E ainda ficam me olhando com umas caras de nojo. [...] Eu não vou sair com uma camiseta: "Sou mãe de autista". Seria uma boa, pelo menos pra não olharem com cara feia, achando que é a gente que não sabe educar um filho, de um filho não saber cumprimentar ou de um filho não querer dar tchau [...]. A questão do preconceito [...] o desafio do [x] e meu (B).

A participante $\mathrm{C}$ trouxe a questão do comportamento do filho como outro desafio, e outras (A e C) também apontam para a questão da autonomia deles. $\mathrm{O}$ estudo de Schmidt (2004) não aborda a configuração familiar monoparental, mas também conclui que um dos desafios para o exercício dessa maternidade é lidar com o comportamento inadequado e a autonomia restrita dos filhos. Os dados da pesquisa de Schmidt, Dell'Aglio e Bosa (2007) apontam que, entre as maiores dificuldades das mães de filhos com autismo no que tange aos cuidados estão as atividades de vida diária, como o vestir-se, realizar a higiene, sair sozinho. "Mais 
difícil na parte do comportamento dele. Agitação, agressividade tinha muito" (C). "A minha preocupação é em relação ao $[\mathrm{x}]$ ter a independência dele" (A).

Também parece ser um aspecto difícil para essas mães o como explicar e, ou, lidar com o filho diante da ausência paterna. Talvez algumas mães ainda sofram, em certa medida, com a falta do companheiro, projetando no filho esse sentimento por não terem (mais) o apoio do pai: "É difícil pra mim, mais difícil pra ele, que pede pelo pai, tá com saudade... E eu fico, às vezes, muito angustiada porque eu não sei nem o que dizer pra ele" (D).

Em relação ao exposto, tanto as mães separadas como as mães viúvas sentem, de certa forma, a ausência paterna como uma perda na vida dos filhos. Assim, observam-se diversas preocupações e desafios enfrentados por essas mães. Diante disso, alguns sentimentos podem emergir com intensidade.

\subsection{Sentimentos vivenciados na experiência de maternidade na monoparentalidade}

Estudos com famílias de crianças diagnosticadas com autismo confirmam a presença de sentimentos que variavam entre tristeza, culpa, insegurança, frustração, preocupação, desamparo e aceitação (Rodrigues, Fonseca \& Silva, 2008; Smeha \& Cezar, 2011). Conforme os dados deste estudo, esses sentimentos podem se tornar ainda mais intensos em decorrência da configuração familiar.

Isso ocorre, possivelmente, por elas não compartilharem suas vivências com pessoas de seu meio, por não se sentirem à vontade para expor seus sentimentos. No caso da participante B, talvez o fato de ter de lidar com a frustração da família em relação ao diagnóstico contribui para que ela não se sinta totalmente à vontade para dividir seus sentimentos.

"Aí, nessas horas que a gente sente falta de ter um companheiro [...]. Eu não queria chegar pro meu pai e pra minha mãe e falar que o $[\mathrm{x}]$ tem esse "detalhezinho"..., mas eu queria ter alguém pra mim sentar e conversar" (B).

Assim, foi possível constatar que, em alguns casos, elas eventualmente pensam na possibilidade de encontrar uma pessoa para um relacionamento amoroso com a qual poderão contar para conversar e expor seus sentimentos. Ainda que considerem uma possibilidade remota, elas não estão em busca de ajuda em relação aos cuidados com o filho, mas do apoio emocional, ou seja, alguém com quem possam desabafar e compartilhar os seus momentos.

Segundo Siqueira, Tubino, Schwarz e Dell'Aglio (2009), a falta de um membro do casal parental pode acarretar em desgaste e sobrecarga àquele que acaba por responsabilizar-se economicamente e emocionalmente no que diz respeito aos 
cuidados demandados pelos filhos. A sobrecarga de cuidados pode ser uma consequência comum a muitas mães que estão inseridas em um contexto de autismo, independentemente do tipo de configuração familiar (Silva \& Ribeiro, 2012; Smeha \& Cezar, 2011).

As dificuldades advindas dos cuidados com esses filhos apresentam significativo impacto à mãe (Rodrigues, Fonseca \& Silva, 2008). Em decorrência deste estudo, é possível sugerir que, no contexto monoparental, a sobrecarga materna pode ser ainda mais intensa, pois as mães viúvas do estudo revelaram que, mesmo quando o marido e pai não era ativamente participativo no cuidado, elas sentiam-se menos sozinhas e sabiam que poderiam contar com eles em uma situação emergencial. Como exemplifica a mãe A: "É, agora realmente mudou muito. Antes, às vezes, até meu marido não ajudava, mas eu sabia que, se eu quisesse, precisasse, ele ia me ajudar".

Embora a viuvez remeta a um certo desamparo, há um sentimento de receio quando é sugerida a ideia de um novo relacionamento. Elas temem que um novo relacionamento possa desequilibrar sua família, como também é apontado na pesquisa de Fialho (2004). As mães C e D deste estudo enxergam essa possibilidade distante ou, como declara a mãe $\mathrm{A}$, impossível. Isso provavelmente em razão de que, nesses casos, esses filhos precisarão de cuidados na vida adulta e também na velhice, demandando tempo, atenção e esforço por parte delas. Assim, a necessidade de cuidado do filho, muitas vezes, permanece ao longo da vida, o que pode interferir na abertura de um espaço para outra pessoa na configuração familiar, contribuindo para a manutenção da monoparentalidade. Conforme a mãe A e D que são viúvas: "Só se eu arranjar um São José... eu acho impossível. A pessoa não vai pensar em te conhecer, conversar, conhecer a tua família [...]. Então acho muito difícil!" (A).

"Não tem como... Agora é eu e ele... Alguém dentro da minha casa eu não vou aceitar, assim... pra ficar junto, ter uma outra... jamais... família não" (D).

Portanto se percebe claramente que os filhos são colocados em primeiro lugar na vida dessas mães. Assim, a situação de monoparentalidade não é alterada:

"Se é pra alguém aparecer na minha vida, que essa pessoa seja muito boa pro [x] e depois pra mim... Abri mão antes de relacionamentos por isso. Fez uma cara feia pro $[\mathrm{x}]$, já não serve pra mim [...], que sou mãe em primeiro lugar” (B).

Aí alguém também não ia querer ficar em segundo, terceiro plano... Aí eu achei melhor ficar só nós dois [...]. Eu acho que seria muito difícil entrar uma pessoa entre nós, porque eu tenho que me dedicar exclusivamente pra ele... Ele precisa de mim [...] É 24 horas (C). 
"Que a gente chega numa certa idade que tu tem um amadurecimento, que essas coisas ficam aquém... que em primeiro lugar é ele" (D).

Outro ponto, levantado pela participante D, aborda especificamente a questão da idade do filho como um fator que contribui para a manutenção da monoparentalidade. $\mathrm{O}$ fato de o filho ser adolescente e de já estar acostumado com a dinâmica da família influencia na decisão de não ter um novo relacionamento amoroso e não imaginar a viabilidade de um recasamento.

E a idade deles: adolescentes. Eles não aceitam. Não é fácil como uma criança de 2, 3, 4 anos [que] vai se moldar conforme [...] Adolescente já não é assim. É bem diferente. A gente não pode dizer "Dessa água eu não vou beber", mas isso lá, aqui dentro não. Aí, ao invés de melhorar, arruma outro problema, piora (D).

Compreende-se, neste estudo, uma dedicação incondicional das mães, na qual há a entrega da própria vida por parte delas em nome dessas responsabilidades, logo não priorizam suas necessidades pessoais. Assim, embora a sobrecarga apareça, também, em estudos sobre mães casadas ou recasadas, acredita-se que, na configuração monoparental, a sobrecarga pode ser agravada até por, muitas vezes, não haver coabitação com um outro adulto que possa auxiliar diretamente na supervisão do filho, para que a mãe consiga dormir, descansar, assistir a um filme, entre outras atividades. Além disso, a mãe foca mais sua atenção e preocupação na vida do filho, já que não há a figura do marido para demandar do seu tempo e da sua atenção. "É, é uma sobrecarga! Sobrecarregada! Sempre, antes, quando eu tinha meu marido, eu achava tão difíceis as coisas. Agora eu vejo: nunca reclamar, porque as coisas podem ficar bem pior e ficam! É difícil e te dá um desânimo" (A).

"Vamos lá! Me desgasto, me quebro, mas... Faz um ano que eu não sei o que é viver a minha vida [...]. Mãe não precisa descansar, não precisa dormir, tomar banho demorado" (B).

Além disso, há outros papéis a serem desempenhados por essa mulher e que interferem nessa sobrecarga, como é o caso da mãe A. Além de cuidar do filho, ela cuida de seus pais: "Tem mais o pai e a mãe que eu cuido. Às vezes, adoece e vai pro Universitário e remédio... Minha mãe tem Alzheimer" (A).

Após a sobrecarga, outro sentimento que se destaca, nas mães entrevistadas, é o medo. Conforme Buscaglia (1997), o medo é outro sentimento frequente nos pais que têm filhos com deficiência, ou seja, um medo natural daquilo que não se entende. Além desse, vem a incerteza quanto ao exercício da parentalidade e ao futuro. Neste estudo, esse medo aparece relacionado a diferentes questôes. A participante $B$ apresenta medo de sua reação diante de uma situação de 
preconceito com o filho; já a participante $C$, no que diz respeito à negligência demonstrada pelo do pai de seu filho. "Tenho medo de dar um tiro em alguém por causa de um preconceito desses" (B). "Tenho medo de deixar sair com ele, porque, pra ele, é o 'rapaz', ele não tem aquela consciência de que ele é especial" (C).

No entanto, observa-se que as mães mencionam o futuro como principal temor diante da condição do filho, como relata a mãe B: "Eu já fui até lá à velhice do $[\mathrm{x}][\ldots]$ e já voltei $[\ldots]$ nessas horas dá vontade de chorar".

Outro aspecto que chama a atenção neste estudo é o amar com tanta intensidade o filho que chega a doer, como relata a mãe B:

"Não sabia que amar doía tanto, que quando eu olhava pro [x] pequenininho, assim... doía. Doía de... sabe? Parecia que eu ia explodir de tão... de tão maravilhoso, de tão gostoso que era ter ele ali, ele mamando, assim, no peito... coisa que eu nunca imaginei que fosse passar" (B).

Parece que quanto mais elas amam, mais sofrem pelo comprometimento decorrente do transtorno e que, em razão do vínculo estabelecido precocemente, antes dos primeiros sinais do autismo, elas queiram fazer o melhor pelo filho, apesar de não ser algo fácil, sobretudo no contexto da monoparentalidade.

Contudo, com o passar do tempo, percebe-se uma reorganização dessas famílias e alguns sentimentos se transformam e são, singularmente, elaborados: "Agora me sinto melhor, mais tranquila, consigo dormir bem à noite, que antes eu não tava conseguindo, né?" (C). No entanto, esse processo de lidar com sentimentos e emoções não é fácil, pois demanda força, insight, sensibilidade (Buscaglia, 1997), mas, nesse sentido, a rede de apoio pode ser uma contribuição significativa.

\subsection{Rede de apoio e suas percepções}

Dentro das funções da rede social, está o apoio social e emocional, a ajuda material e a de serviços, guia cognitivo e conselhos, entre outros. Essa "rede social pessoal" ou "rede social significativa" inclui o conjunto de vínculos interpessoais, ou seja, família, amigos, relaçôes de trabalho, de inserção comunitária e de práticas sociais, os quais podem contribuir para o bem-estar e consolidação dos potenciais de mudança (Sluzki, 1997).

O estudo de Souza, Rocha e Santos (2011), ao descrever as experiências de mães no cuidado de crianças com TEA, identificou-se a relevância do auxílio em relação ao cuidado compartilhado, já que, com um apoio familiar, os cuidados demandados tornam-se menos difíceis, não sobrecarregando tanto a figura 
materna. No caso deste estudo, mesmo o pouco envolvimento do pai no cuidado com o filho, este era valorizado pelas mães, atualmente viúvas. Isto é, quando tinham o companheiro, sabiam que poderiam recorrer a ele em momentos de maior necessidade, sentindo essa diferença após ficarem viúvas, o que pode ser exemplificado na seguinte fala: "A diferença é que antes tu podia dar um telefonema... tu podia contar com aquela pessoa do teu lado. De um jeito ou de outro, dava um jeitinho... agora não tenho mais" (D).

E não apenas nos cuidados com o filho com TEA, mas quanto o apoio por parte dos maridos auxiliava de outros modos, minimizando a sobrecarga diante dos afazeres: "Eu tava acostumada com o meu marido, assim, aquele jardim... eu tinha um jardim. Agora, estraga uma coisa eu tenho que sair a arrumar... eu não sei... com quem, a quem recorrer" (A).

Quando se trata de filhos que apresentam diagnóstico de autismo, é importante que as mães possam contar com o auxílio de outras pessoas e, ou, instituições. Na pesquisa de Moreira e Sarriera (2008), ainda que os dados não tenham sido coletados com famílias de pessoas com autismo, eles apontam que a família de origem pode se apresentar como um papel relevante como apoio, pois a "casa dos pais" pode tornar-se uma estrutura fundamental para determinados momentos, já que esses pais podem ajudar nos cuidados com a criança e no suporte emocional. Já com as mães deste estudo, a família de origem é levada em consideração, dentro da rede de apoio, em apenas um caso (B): "Como eu dependo do meu pai pra levar o [x] nas coisas [...]; que nem hoje, a mãe foi no zoológico com ele [...] Disso eu não posso participar. Se não fossem meus pais, eu não teria hoje um tratamento pro meu filho" (B).

Compreende-se que a mãe B é a mais jovem das entrevistadas e, com sua idade, ela conta com o auxílio dos pais que ainda são jovens e têm saúde para prover ajuda. Já as participantes A, C e D, por serem mais velhas, parece que não podem mais contar com o apoio de seus pais. Em alguns casos, já são falecidos e, em outros, como refere a participante $\mathrm{A}$, ocorre ao contrário, ela precisa assumir o papel de cuidadora desses pais, atualmente bastante idosos: "Tem mais o pai e a mãe que eu cuido" (A).

Assim, ela conta com o apoio do outro filho e de um sobrinho. Contudo se percebe que é uma ajuda em situação mais "emergencial" e não um auxílio no cotidiano, como no caso da participante $\mathrm{C}$, cujo apoio advém mais por parte da irmã. "Eu até posso contar com o meu filho; peço, mas eu já tô louca pra me organizar... meu sobrinho ajuda também; às vezes, meu sobrinho perde a paciência" (A). "A minha irmã me ajuda, mas quando dá..., quando a gente precisa, que ele não tá bem, se ela pode, ela vai com a gente pra comprar alguma coisa" (C). 
Além da família, os amigos acabam, em algumas situações, fazendo parte dessa rede de apoio. A participante $\mathrm{D}$ sinaliza a família, os amigos e, principalmente, a cuidadora do filho como um forte apoio. Por outro lado, ela salienta também a fé como um apoio fundamental. "Aqui é o exemplo [cuidadora]. A gente briga, mas é uma pessoa que eu posso contar... a gente não se sente sozinha... tem parentes, tem amigos... que na hora que preciso... me ajudam... Eu me sinto porque eu tenho muita fé" (D). "Hoje, as pessoas que mais me apoiam são minhas amigas, amigos e o meu pai e a minha mãe. Não tenho base sem eles" (B).

De acordo com Semensato e Bosa (2013), a rede de apoio tende a ser percebida como fundamental na reestruturação familiar, desde o lidar com o diagnóstico até possíveis intervenções; sendo essas representadas, em alguns casos, pelos profissionais e serviços de saúde. Evidenciou-se, em contrapartida, que a relação com os profissionais pode ser vista como fonte de estresse, mas também, em outros, como uma aliança, que é o caso da mãe B. Ela relata: "Eu tenho a [nome da educadora especial], que eu converso muito" (B). No entanto, essas intervenções clínicas são citadas em outro caso, como uma ajuda à disposição momentaneamente, mas não são percebidas, necessariamente, fazendo parte da rede de apoio: "Das terapias, assim, mas é aquela coisa ali. Eu não vou dizer, por exemplo: vem aqui hoje que eu não posso, vem aqui em casa ficar com o [x]” (A).

Logo, percebe-se a importância da rede de poio durante essa vivência e contexto. O estudo de Giallo, Wood, Jellett e Porter (2013) mostra que as mães de filhos com autismo que apontaram uma necessidade elevada de apoio social também demonstraram altos níveis de fadiga/cansaço. Segundo pesquisa de Serra (2012), o cansaço e a sobrecarga são mencionados por um não possível compartilhamento dos cuidados com o filho devido a uma falta de solidariedade entre os membros da família na percepção dessas mães. Na pesquisa de Borges e Boeckel (2010) sobre impacto do TEA às mães, também constata inexistência de suporte social e o cansaço como fazendo parte de seu dia a dia. No caso deste estudo, visualizase o quanto essa rede pode se tornar um diferencial na responsividade materna. Isso, especialmente, em uma configuração monoparental.

\section{CONSIDERAÇÕES FINAIS}

Por meio deste estudo, foi possível constatar que há semelhanças entre as experiências de mães de filhos com autismo no contexto familiar, no qual elas estão casadas com o pai ou recasadas, com a configuração monoparental. São exemplos disso a sobrecarga na rotina de cuidados, alguns sentimentos relacionados ao excesso de responsabilidade, a percepção da importância da rede de apoio, entre 
outros. Embora haja essas semelhanças, acredita-se que a diferença possa estar na intensidade, isto é, na monoparentalidade, as dificuldades podem ser agravadas pela ausência de um companheiro com quem possam compartilhar a rotina.

$\mathrm{O}$ estudo permitiu identificar situações diferentes que deram origem à família de configuração monoparental. Nele participaram duas mães separadas do cônjuge e duas mães viúvas. Ambos são contextos monoparentais, mas que também têm suas especificidades. Nesse aspecto, nota-se que as mães viúvas vivenciaram um outro tipo de configuração anterior que finalizou com a morte dos maridos. Assim, elas relataram uma memória positiva de apoio. Ainda que a participação paterna se restringia a situaçooes mais emergenciais, esse pai, de certa forma, compartilhava o cuidado com o filho, diferentemente das duas mães separadas. Para estas últimas, o tempo de convivência com o marido não representava um apoio significativo.

A literatura descreve, em geral, que as mães que têm filhos com autismo tendem a optar por se dedicarem, exclusivamente, aos cuidados que promoverão o desenvolvimento deles. Ainda que algumas mães deste estudo tenham abdicado de uma vida profissional, não foi possível identificar uma relação direta entre essa decisão e a monoparentalidade. Em contrapartida, pode se supor que as mães deste estudo que trabalham fora do ambiente doméstico podem ter como uma das motivações a necessidade de subsidiar os gastos com o filho, já que não podem contar com a participação financeira de um companheiro, ou seja, é uma necessidade também advinda dessa configuração familiar.

Os resultados deste estudo revelam que há várias razões para a manutenção da monoparentalidade, entre elas, a preponderância do papel de mãe em detrimento do papel de mulher, a fragilidade da rede de apoio e a fase de adolescência do filho. A adolescência pode ser uma fase difícil e complexa no contexto do autismo, podendo tornar-se um impedimento para a inserção de um novo membro no sistema familiar. Por outro lado, quando as mães pensavam na possibilidade de virem a ter um novo relacionamento, mesmo salientando que essa era uma ideia muito remota, o que elas buscavam não era uma ajuda em relação aos cuidados com o filho, mas almejavam ter um apoio emocional, ou seja, alguém com quem pudessem dividir sentimentos, conversar, desabafar e, ou, compartilhar momentos e preocupações.

Em relação à percepção de apoio, o estudo identificou que, mesmo havendo diferenças nas percepções de rede de apoio e de onde esta advinha, ela parecia ser predominantemente fraca. Isso podia estar relacionado à ausência de um companheiro e, em algumas situações, a ausência de uma relação amorosa somava-se ao fato de não poder contar com a família de origem para ajudar na rotina de cuidados do filho com autismo. 
Além disso, considerando que três dos filhos eram adolescentes, os dados sugerem que, na fase da adolescência desses filhos com TEA, poderia ocorrer uma redução significativa do apoio. Isso porque, nessa faixa etária, o comportamento estava mais estruturado em termos de rotina, havia um funcionamento menos flexível que, provavelmente, somente as pessoas que conviviam conheciam e sabiam lidar. Assim, na infância, havia mais facilmente voluntários para o apoio no cuidado; já na adolescência, poderia ocorrer certo receio dos possíveis cuidadores de não saberem como atender às demandas, considerando que, muitas vezes, havia um prejuízo na fala. Ainda, haveria um corpo praticamente adulto com características próprias da adolescência e, ao mesmo tempo, haveria necessidade de cuidados básicos, como auxílio no banho, alimentação e higiene pessoal.

Assim, a experiência de maternidade especialmente nesse contexto familiar é, muitas vezes, solitária e demanda muitas responsabilidades. Por isso, compete aos profissionais da saúde e educação, primordialmente aos psicólogos, promover a ampliação e o fortalecimento da rede que elas percebem como apoio. Desse modo, essa seria uma importante contribuição para minimizar a sobrecarga advinda dessa experiência.

Para finalizar, considerando que, no Município onde foi realizado o estudo, não havia um serviço integrado, público e de qualidade, foi possível perceber a necessidade da construção de um centro de atendimento multiprofissional, especializado no tratamento de autismo, onde as mães pudessem encontrar acolhimento, informação, orientação, apoio e profissionais capacitados para atender a pessoa com diagnóstico de TEA e a família. 


\section{REFERÊNCIAS}

American Psychiatric Association (2014). Manual diagnóstico e estatístico de transtornos mentais (DSM-5). (5a ed.). Porto Alegre: Artmed.

Borges, H. C. M. \& Boeckel, M. G. (2010). O impacto do transtorno autista na vida das mães dos portadores. (Trabalho de Conclusão de Curso). Faculdades Integradas de Taquara, Taquara, RS.

Brazelton, T. B. \& Cramer, B. G. (1992). As primeiras relaçôes. São Paulo: Martins Fontes.

Buscaglia, L. (1997). Os deficientes e seus pais: um desafio ao aconselhamento. Rio de Janeiro: Record.

Correia, I. M. (2002). Famílias monoparentais: uma família, um caso... Revista Portuguesa de Medicina Geral e Familiar, 18(4), 241-249.

Fialho, R. C. B. (2004). Enfoques sociais da familia monoparental. (Trabalho de Conclusão de Curso). Universidade Cândido Mendes, Pós-Graduação "Latu Sensu" em Docência do Ensino Superior, Rio de Janeiro.

Giallo, R., Wood, C. E., Jellett, R. \& Porter, R. (2013). Fatigue, wellbeing and parental self-efficacy in mothers of children with an Autism Spectrum Disorder. Autism, 17(4), 465-480.

Graça, S. (2011). Vivências dos pais de crianças com perturbação do espectro autista: representações parentais. International Journal of Developmental and Educational Psychology. INFAD Revista de Psicologia, 4(1), 541-550.

Grael, P. M. (2007). Expressão de afeto em genitores masculinos de crianças autistas. In F. B. Assumpção Júnior \& E. Kuczynski, E. (Eds.), Autismo infantil: novas tendências e perspectivas. (pp. 239-254). São Paulo: Atheneu.

Hernández, A. B., Gutiérrez, M. C., Zamalloa, M. P. \& Mathews, Z. S. (2012). Experiencias de los padres ante el cuidado de su hijo autista. Revista Enfermería Herediana, 5(1), 26-36.

Hernández, M. A. (2013). Origen del concepto de monoparentalidad: un ejercicio de contextualización sociohistórica. Papers, 98(2), 263-285.

Instituto Brasileiro de Geografia e Estatística (2010). Censo demográfico famílias e domicílios: resultados da amostra. Rio de Janeiro: IBGE. 
Leite, E. de O. (1997). Famílias monoparentais: a situação jurídica de pais e mães solteiros, de pais e mães separados e dos filhos na ruptura da vida conjugal. São Paulo: Revista dos Tribunais.

Lôbo, P. (2009). Direito Civil: famílias. (2a ed.). São Paulo: Saraiva.

Lucas, M. C. S. (2012). Forças nas famílias monoparentais femininas. (Dissertação de Mestrado). Instituto Superior Miguel Torga, Escola Superior de Altos Estudos. Coimbra.

Marin, A. \& Piccinini, C. A. (2009, outubro-dezembro). Famílias uniparentais: a mãe solteira na literatura. Psico, 40(4), 422-429. Recuperado a partir de http:// revistaseletronicas. pucrs.br/ojs/index.php/revistapsico/article/view/2683

Marques, M. H. \& Dixe, M. dos A. R. (2011). Crianças e jovens autistas: impacto na dinâmica familiar e pessoal de seus pais. Revista de Psiquiatria Clinica, 38(2), 66-70.

Minatel, M. M. \& Matsukura, T. S. (2014, maio-agosto). Famílias de crianças e adolescentes com autismo: cotidiano e realidade de cuidados em diferentes etapas do desenvolvimento. Revista de Terapia Ocupacional da Universidade de São Paulo, 25(2), 126-134.

Moraes, R. (2003). Uma tempestade de luz: a compreensão possibilitada pela análise textual discursiva. Ciência e Educação, 9(2), 191-211.

Moreira, M. C. \& Sarriera, J. C. (2008, outubro-dezembro). Satisfação e composição da rede de apoio social a gestantes adolescentes. Psicologia em Estudo, 13(4), 781-789.

Palma, R. (2001). Famílias monoparentais. Rio de Janeiro: Forense.

Rapoport, A. \& Piccinini, C.A. (2006). Apoio social e experiência da maternidade. Revista Brasileira de Crescimento e Desenvolvimento Humano, 16(1), 85-96.

Rodrigues, L. R., Fonseca, M de O. \& Silva, F. F. (2008). Convivendo com a criança autista: sentimentos da família. Revista Mineira de Enfermagem, 12(3), 321-327.

Schmidt, C. (2004). Estresse, autoeficácia e o contexto de adaptação familiar de mães de portadores de transtornos globais do desenvolvimento. (Dissertação de Mestrado). Universidade Federal do Rio Grande do Sul, Programa de PósGraduação em Psicologia, Porto Alegre. 
Schmidt, C. \& Bosa, C. (2003, julho-dezembro). A investigação do impacto do autismo na família: revisão crítica da literatura e proposta de um novo modelo. Interação em Psicologia, 7(2), 111-120.

Schmidt, C. \& Bosa, C. (2007). Estresse e autoeficácia em mães de pessoas com autismo. Arquivos Brasileiros de Psicologia, 59(2), 179-191.

Schmidt, C., Dell'Aglio, D. D. \& Bosa, C. A. (2007). Estratégias de coping de mães de portadores de autismo: lidando com dificuldades e com a emoção. Psicologia: Reflexão e Crítica, 20(1), 124-131.

Semensato, M. R. \& Bosa, C. A. (2013, setembro-dezembro). Relatos de pais de crianças com autismo sobre a rede de apoio formal: aspectos da elaboração parental do diagnóstico. Revista Educação Especial, 26(47), 651-664.

Serra, D. (2012, março). Autismo, família e inclusão. Polêmica, 9(1), 40-56.

Silva, E. B. A. da. \& Ribeiro, M. F. M. (2012, outubro-dezembro). Aprendendo a ser mãe de uma criança autista. Estudos, 39(4), 579-589.

Silva, M. S. da. (2010). Construção de significados da maternidade por mães de autistas. (Dissertação de Mestrado). Universidade Federal da Bahia, Instituto de Psicologia, Salvador.

Siqueira, A. C., Tubino, C. de. L., Schwarz, C. \& Dell'Aglio, D. D. (2009). Percepção das figuras parentais na rede de apoio de crianças e adolescentes institucionalizados. Arquivos Brasileiros de Psicologia, 61(1), 176-190.

Sluzki, C. E. (1997). A rede social na prática sistêmica: alternativas terapêuticas. São Paulo: Casa do Psicólogo.

Smeha, L. N. \& Cezar, P. K. (2011, janeiro-março). A vivência da maternidade de mães de crianças com autismo. Psicologia em Estudo, 16(1), 43-50.

Souza, A. M. de, Rocha, M. O. da \& Santos, W. C. (2011). Experiências de mães no cuidado com filhos autistas. Revista Interdisciplinar Novafapi, 4(2), 35-39.

Sprovieri, M. H. S. (2007). Estresse, alexitimia e dinâmica familiar de portadores de autismo. In F. B. A. Assumpção Júnior \& E. Kuczynski (Eds.), Autismo infantil: novas tendências e perspectivas. (pp. 207-238). São Paulo: Atheneu. 
Sprovieri, M. H. S. \& Assumpção Júnior, F. B. (2001). Dinâmica familiar de crianças autistas. Arquivos de Neuropsiquiatria, 59(2-A), 230-237.

Verdi, M. T. (2003). Grupo de pais de crianças autistas: tessitura dos vínculos. Revista da Sociedade de Psicoterapias Analíticas Grupais do Estado de São Paulo, 4(4), 110-114.

Yunes, M. A. M., Garcia, N. M. \& Albuquerque, B. de M. (2007). Monoparentalidade, pobreza e resiliência: entre as crenças dos profissionais e as possibilidades da convivência familiar. Psicologia: Reflexão e Crítica, 20(3), 444-453. 